111

\author{
اتجاهات الزراع نحو عودة الدورة الزراعية الإجبارية ببعض قرى محافظة المنيا \\ د/ ممدي محمد معوض الثريف \\ باحث بمعهد بحوث الإرشاد الزراعي و التتمية الريفية ـ قسم بحوث البرامج الإرشادية
}

استهدف البحث تحديد مستوى اتجاهات الزراع المبحوثين نحو عودة الدورة الزر اعية الإجبارية،

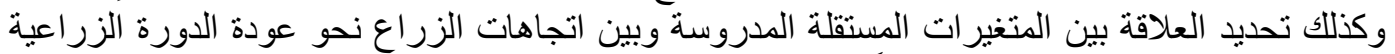

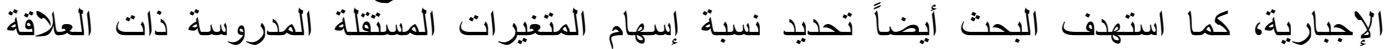

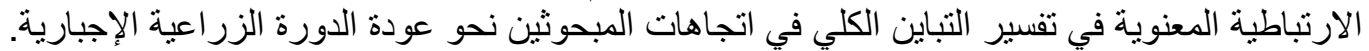

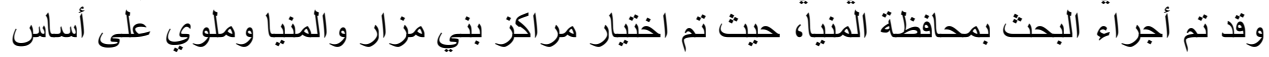

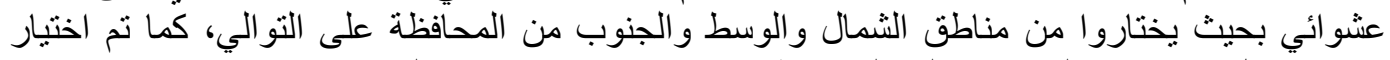

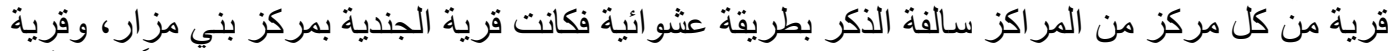

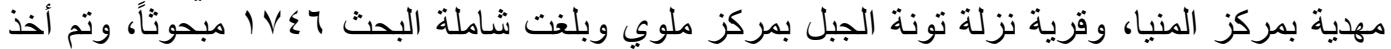

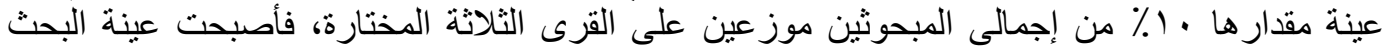

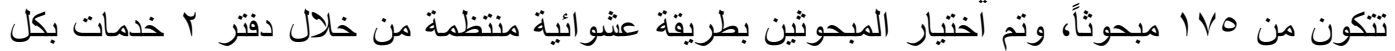

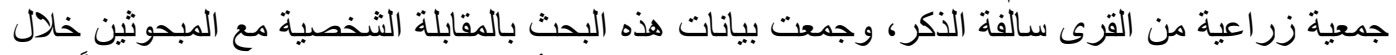

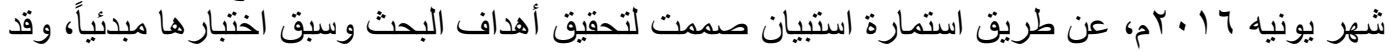
تم استخدام التكرارات والنسب المئوية ومعامل الارنباط البسيط لبيرسون ومربع كاي ومعامل التوافق التقان

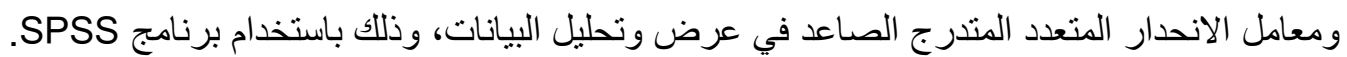

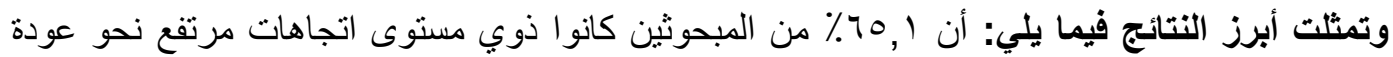

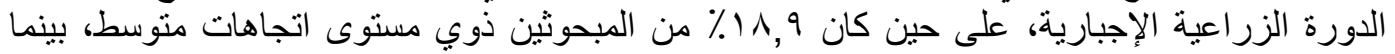

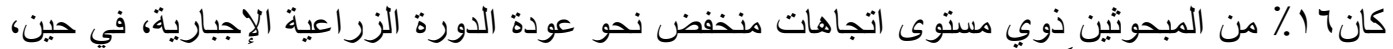

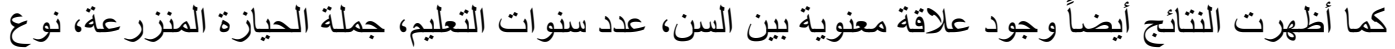

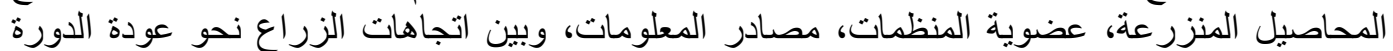

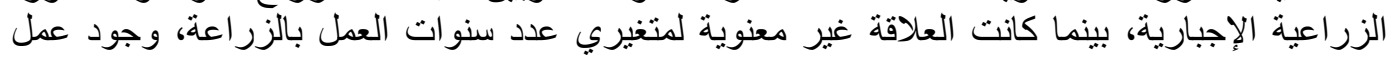
بجانب الزر اعة.

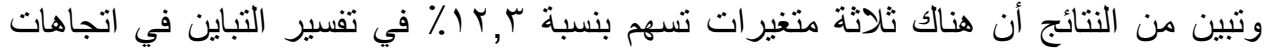

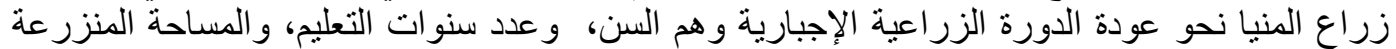

المقدمة والإطار النظري: المان:

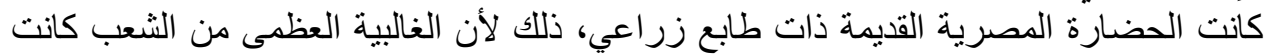

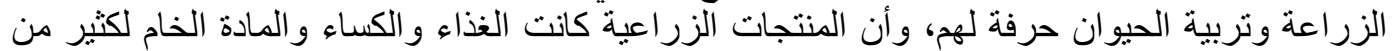

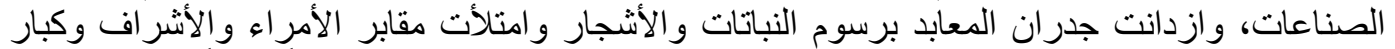

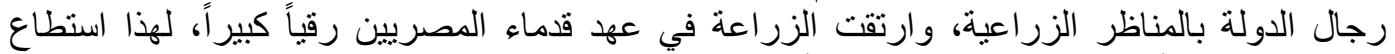

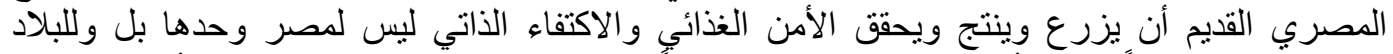
المجاورة لها. فكثيراً ما التجأ إليها سكان بلاد الثام طلباً للحبوب و الغذاء فمصر جنة الله في أرضهاء، وجاء ولاء

Fayoum J. Agric. Res. \& Dev., Vol. 30, No.2, July, 2016 
119

في سفر التكوين " وجاءت كل الأرض إلى مصر إلى يوسف لتشتري قمحاً، لأن الجوع كان شديد في كل

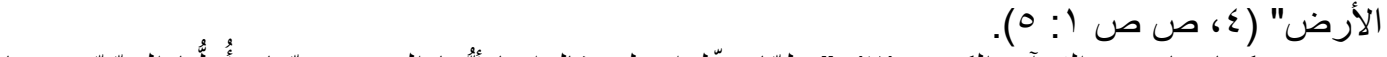

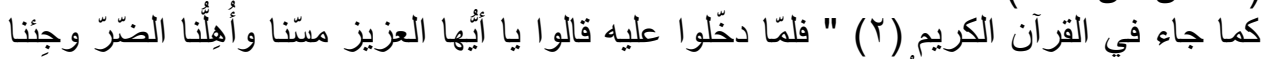

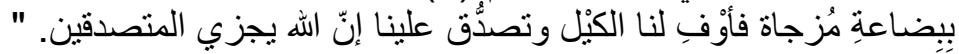

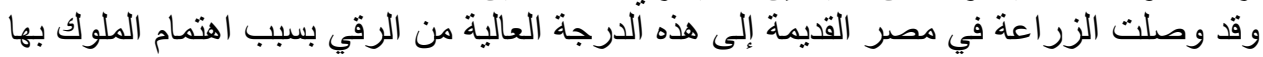

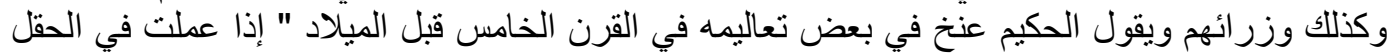

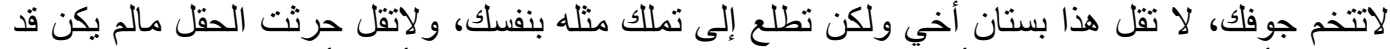

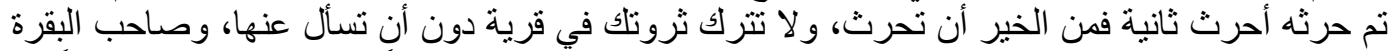

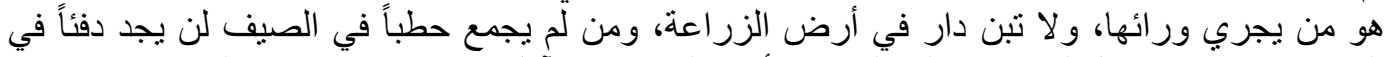

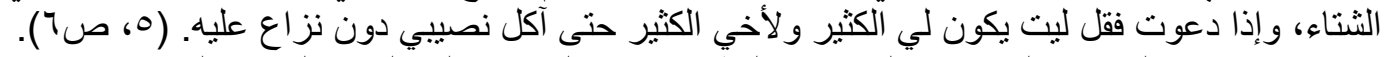

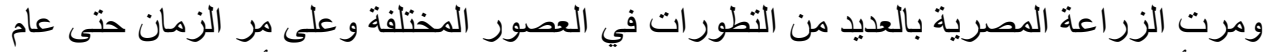

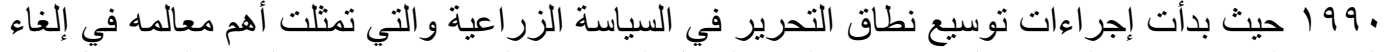

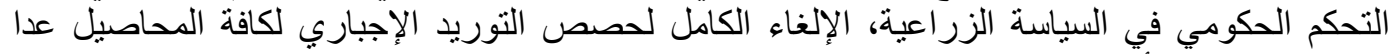

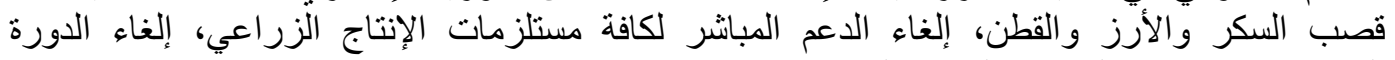

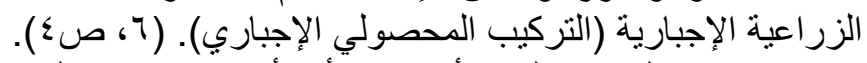

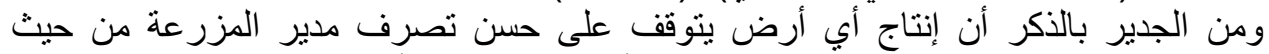

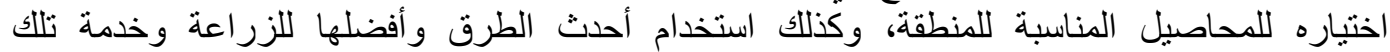

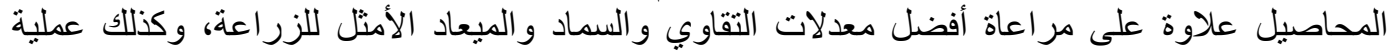

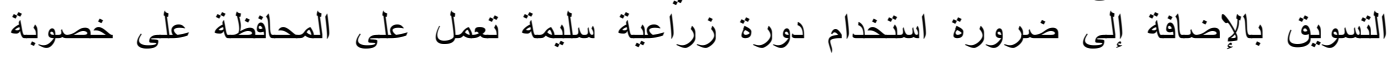

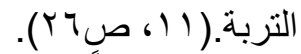

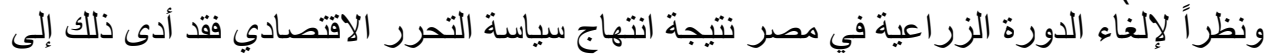

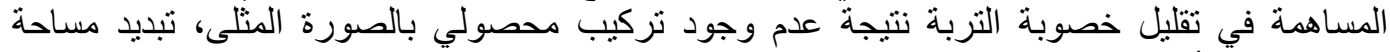

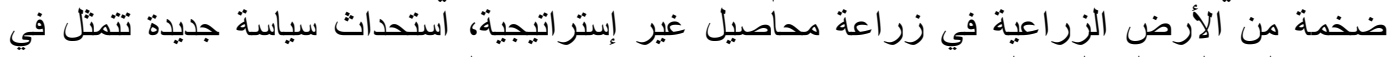

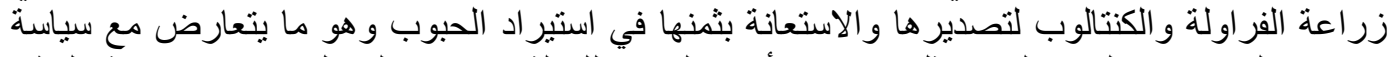

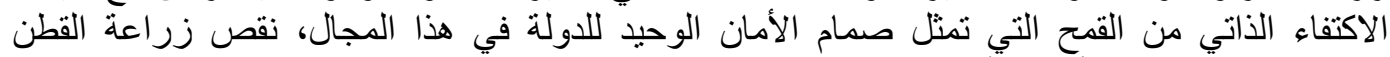

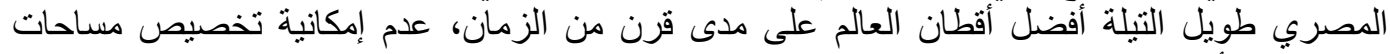

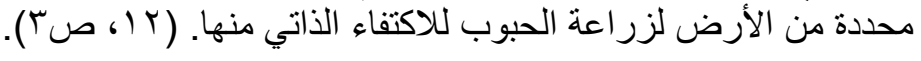

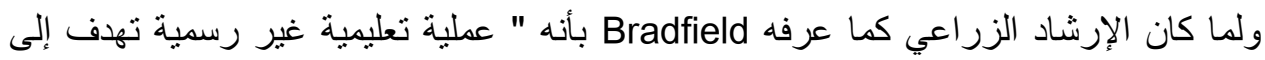
تعليم أهل الريف كيفية استغلال جهودهم الذاتية للارتقاء والنهوض بمستوى معيشتهم، وذللك عن طرئ الإنيق

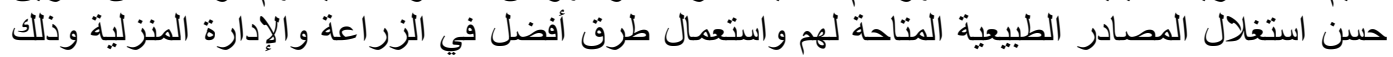

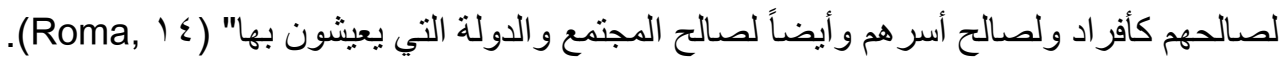

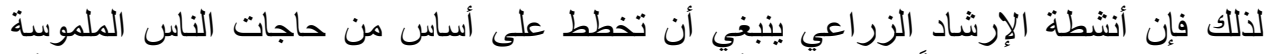

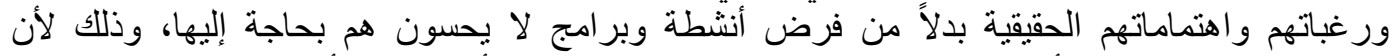

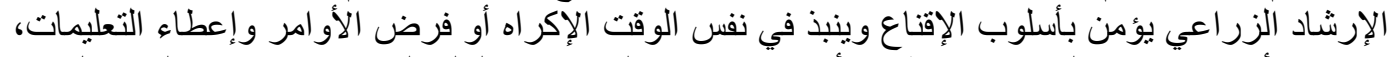

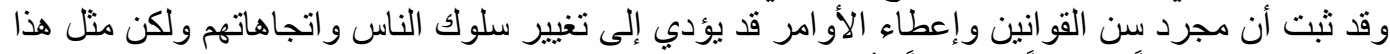

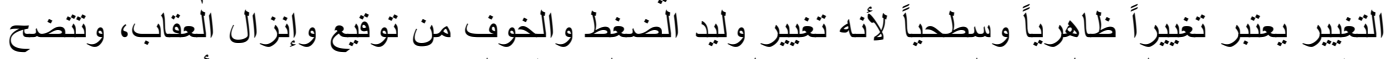

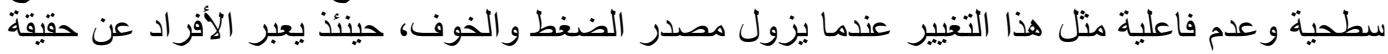

Fayoum J. Agric. Res. \& Dev., Vol. 30, No.2, July, 2016 
$1 \%$.

نو اياهم و اتجاهاتهم وميولهم تعبير أ يؤكد أن جذور مثل هذا التغيير غير عميقة لأنها لم تحدث نتيجة الإقناع

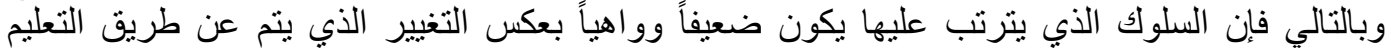

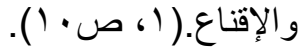

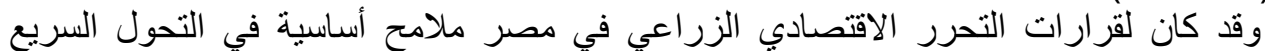

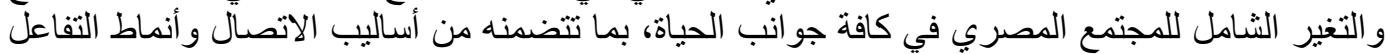

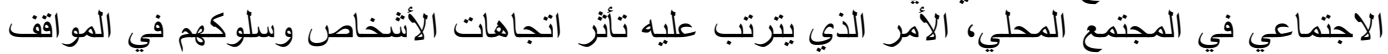

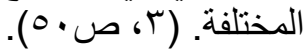

وقد أوضحت در اسات العلماء للاتجاهات ومحاولة تعريفها وتحليل عناصر ها وجود قدر كبير من

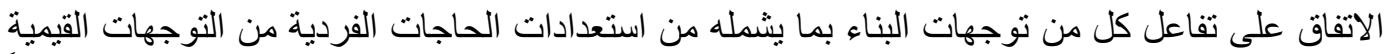

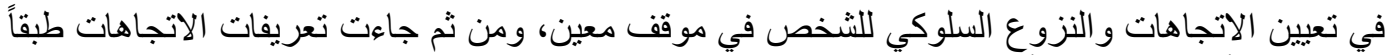

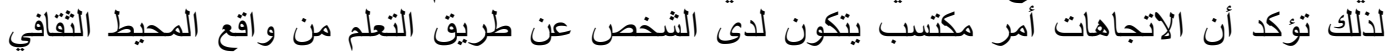

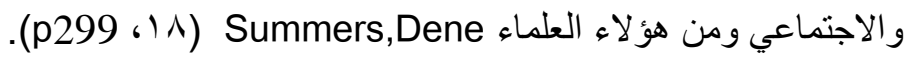

كما يعرف All port الاتجاهات بأنها " استعداد أو نزوع مسبق للاستجابة بطريقة معينة نحو موضوع أو

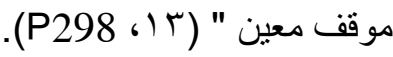

وقد ذهب كاتز وغيره Scotland، Katz إلى أن الاتجاهات هي ميل الفرد لتقييم موضوع أو

رمز بطريقة معينة، وهو تعريف نفسي يربط الاتجاهات بالخصائص النفسية.(10، P.12)، أما الاجتماعيين ومنهم Wagner فيربطون الاتجاهات بالسياق الثقافي وتوجهات القيم، ومن ذلك أيضاً ما قدمه بـان

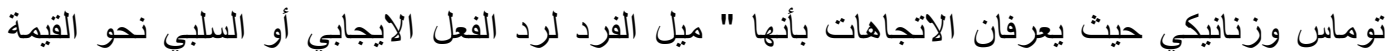

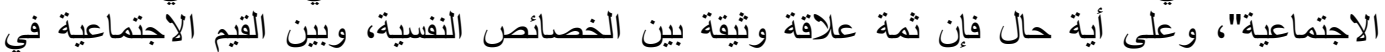

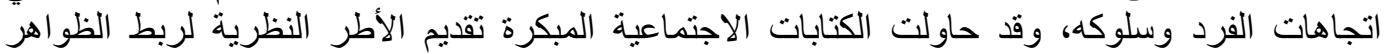

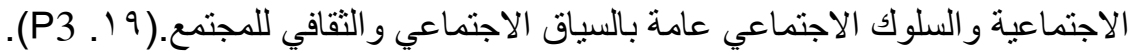

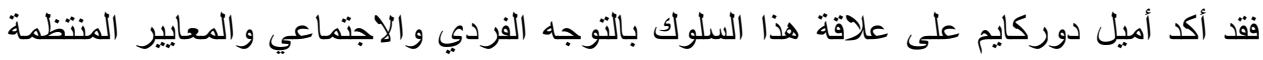

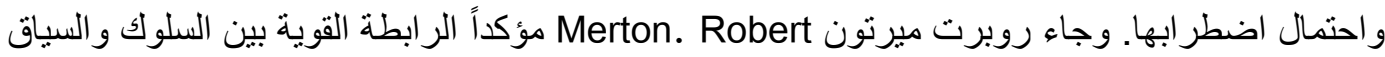

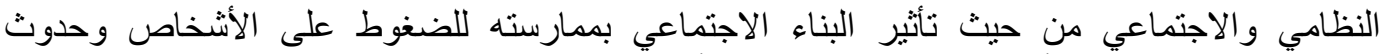

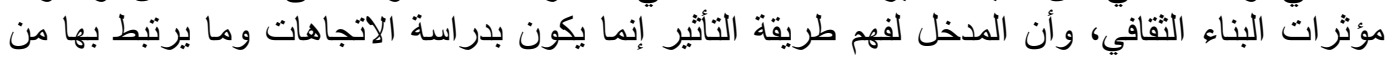

أنماط الاستجابة نحو عناصر الثقافة.(7 (132، (Pp131.132).

ومن ناحية أخرى فإن Persons يقرر أن النظام الاجتماعي ينطوي على دمج توجهات القيم في

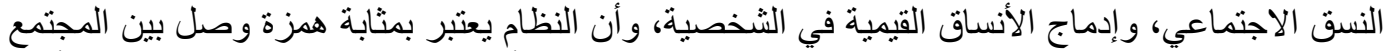

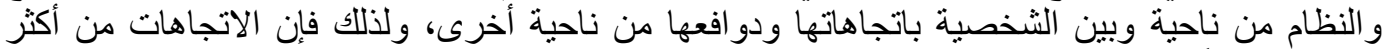

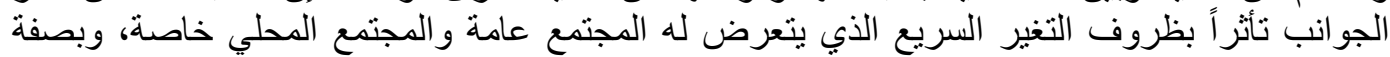

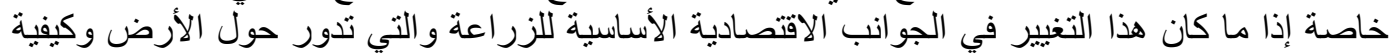

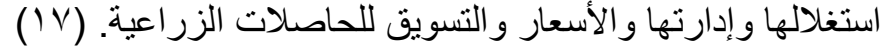

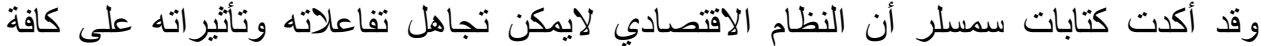

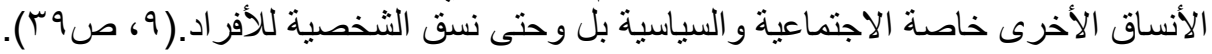

Fayoum J. Agric. Res. \& Dev., Vol. 30, No.2, July, 2016 
||$_{1}$

وذكر زهران عن كاتز Katz أن الاتجاهات تحدد طريق السلوك وتفسره، كما أنها تنظم العمليات

الدافعية والانفعالية والإدر اكية والمعرفية حول بعض النواحي الموجودة في المجال الذي يعيش فيه الفرد،

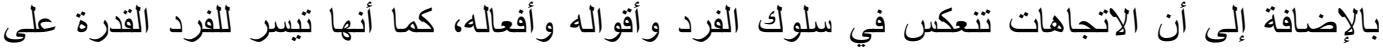
السلوك و اتخاذ القرار ات في المو اقف النفسية المتعددة في شئ من الاتساق و التوحيد، وتوضك الته الاتجاهات

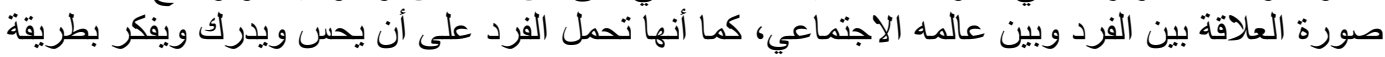

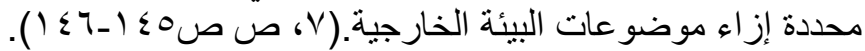

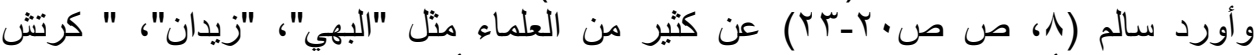
و آخرون"، "جوزفين"، أن طبيعة الاتجاهات تتحد من خلال خمسة أبعاد رئيسية وهي: الوجهة، القوة، الوضوح، المدى، الاستقلال. وتتكون الاتجاهات من ثلاثة مكونات تتفاعل مع بعضها البعض وهيى: ا- المكون المعرفي Cognitive Component: وهو مجموعة من الأفكار والمعتقدات والآراء التي تكونت من إدرالك الشخص لموضوع ما نتيجة للخبرة والمعرفة السابقة التي حصل عليها الفرد من احتكاكه بالبيئة المحيطة الدرن.

Y- المكون العاطفي أو الشعوري Affective Component : وهو عبارة عن مشاعر الشخص ورغباته نحو الموضوع و إقباله عليه أو نفوره منهي rـ المكون السلوكي Behavioral Component: وهو الاستعداد السلوكي الفعلي تجاه الموضو ع بطريقة

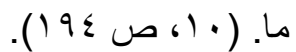

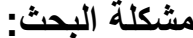

تعتبر الزراعة الركيزة الأساسية لغذاء الإنسان لما تتميز به من إنتاج الطاقة والغذاء ليس في

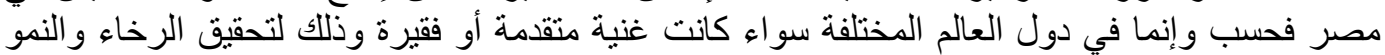
الصناعي أو التصدير أو سد احتياجات السكان المتزايدة من الغذاء، وتعتبر الإدارة الجيدة للمزرة عة أو أو أو

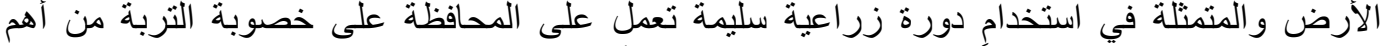

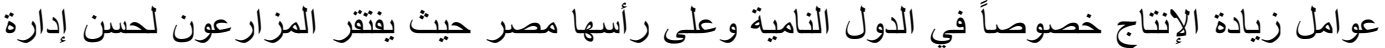
مزارعهم مما يتسبب في ضعف الإنتاج، وقد تعالت الأصوات الإن المنادية بضرورة فودة فوة الدورة الزراعية الإجبارية في الآونة الأخيرة من قبل بعض المزار ارعين نظرا لفشلهم في تخطيط دورات زراعية مناسبة

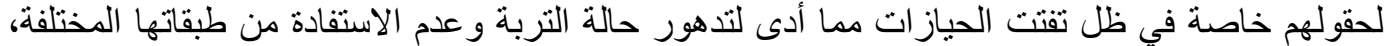

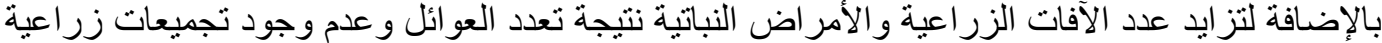

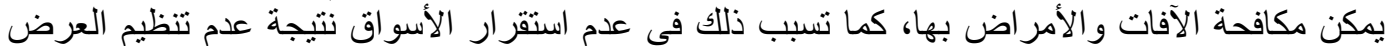
و الطلب لعدم وجود سياسة زراعية منظمه ومحكمة، ولما كانت الاتجاهات هي مجموعة من الأفكار و المعتقدات والآر اء التي تكونت من إدر الك الثخص لموضوع معين نتيجة الخبرة و المعرفة السابقة التي التي

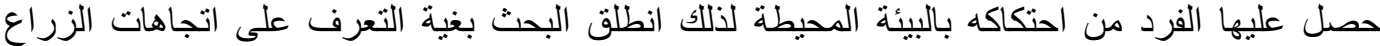
بمحافظة المنيا نحو عودة الدورة الزرا اعية الإجبارية.

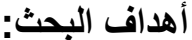

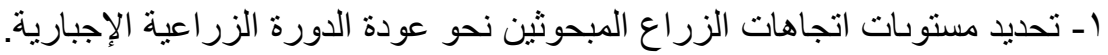

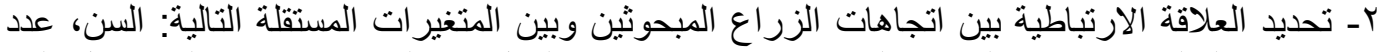

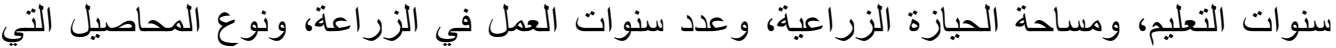

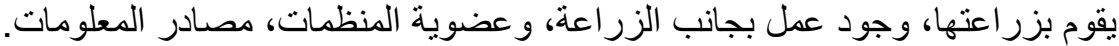

Fayoum J. Agric. Res. \& Dev., Vol. 30, No.2, July, 2016 
ITY

r- تحديد نسبة إسهام المتغير ات المستقلة ذات الارتباط المعنوي في تفسير التباين لاتجاهات الزراع نحو عودة الدورة الزر اعية الإجبارية. الفروض البحثية لتحقيق الهدفين الثالث و الر ابع من البحث نم صياغة الفرضين البحثيين الآتيين :-

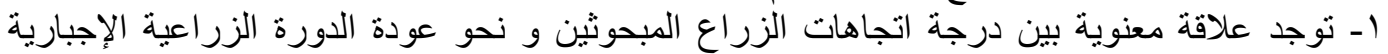

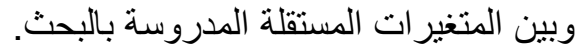

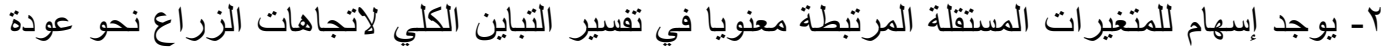
الدورة الزر اعية الإجبارية. الطريقة البحثية منطقة البحث

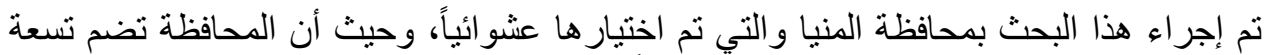

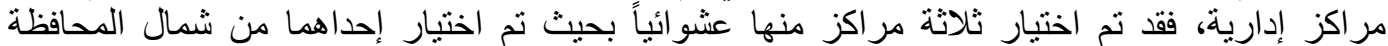

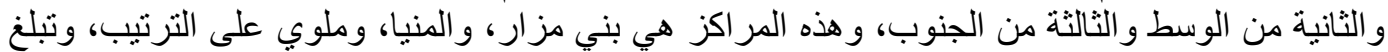

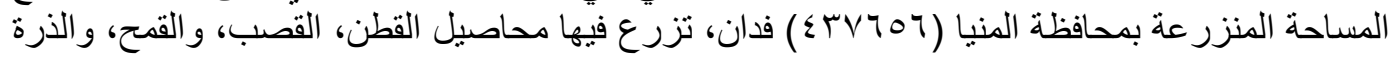

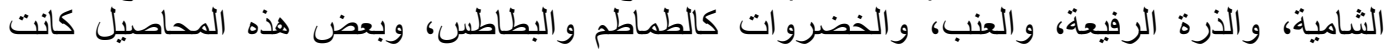

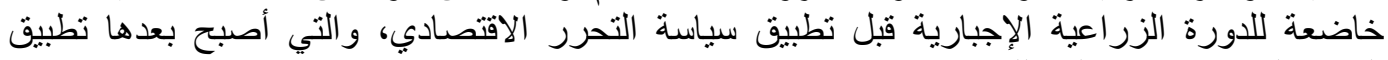

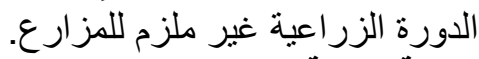

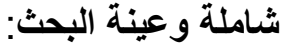

تم اختيار قرية من كل مركز من المر اكز اكن سالفة الذكر بطريقة عشوائية فكانت قرية الجندية

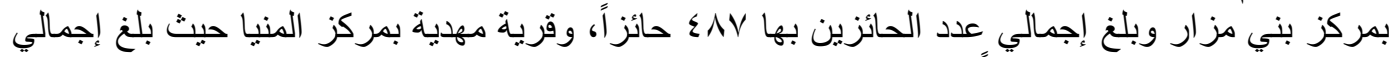

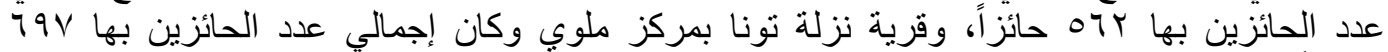

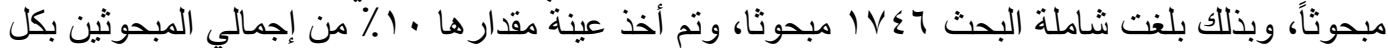

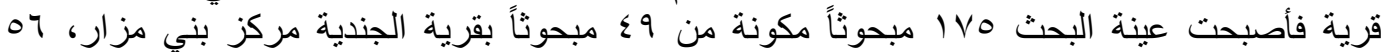

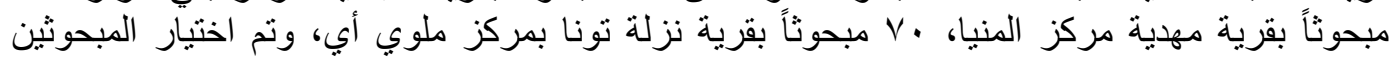

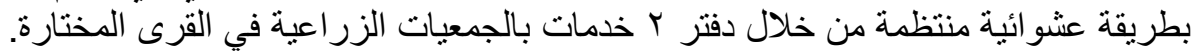

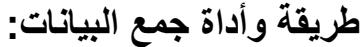

جمعت بيانات البحث عن طريق استمارة استبيان بالمقابلة الشخصية مع المبحوثين والتي تضمنت

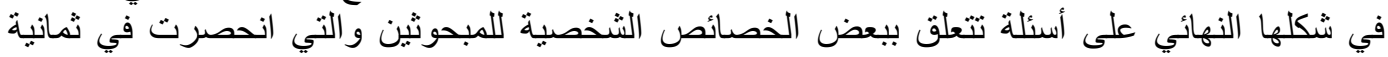

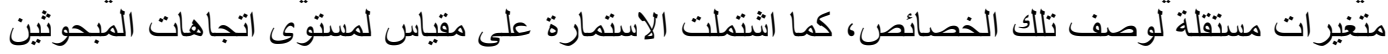
نحو عودة الدورة الزراعية الإجبارية. هذا وبعد الانتهاء من وضع الإنة الاستمارة في شكلها النهائي، تم إجراء اختبار مبلئي للاستمارة

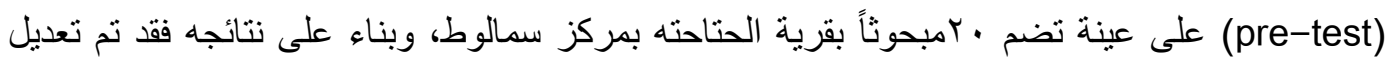

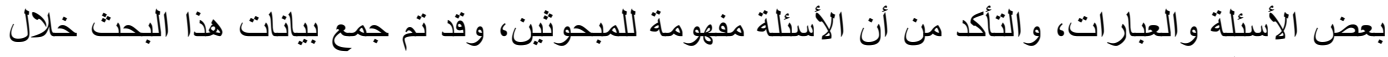
هذا وقد استخدمت عدة أساليب إحصائية لتحليل بيانات البحث وتمثلت في معامل الارتباط البسيط

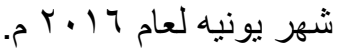

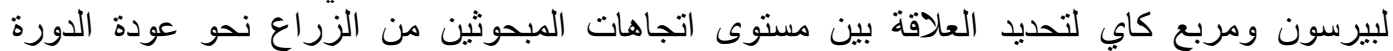

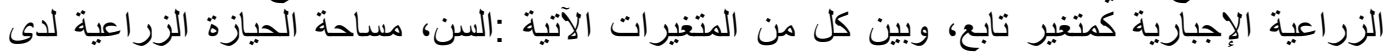

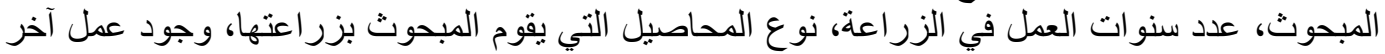

Fayoum J. Agric. Res. \& Dev., Vol. 30, No.2, July, 2016 
Tr

بجانب الزر اعة، عضوية المنظمات، مصادر المعلومات، كما تم استخدام معامل التوافق ومعامل الانحدار

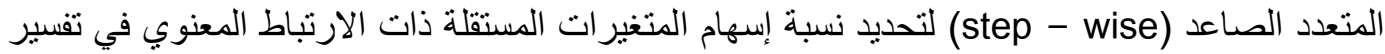

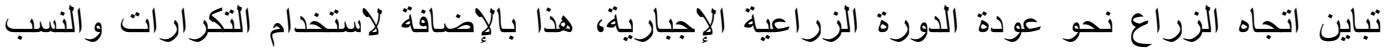
المئوية في عرض آنجاه النتائج. المعالجة الكمية للبيانات أولا : المتغيرات المستقلة المبتة

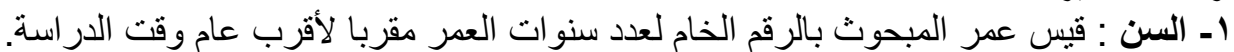

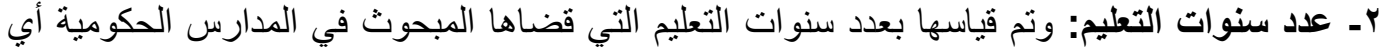

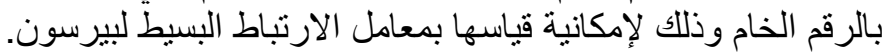

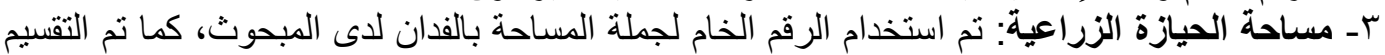

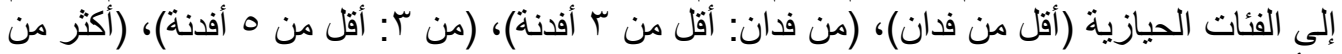

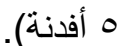
ع ـ سنوات العمل في الزراعة: تم قياس المتغير بوضع الرقم الخام لعدد السنوات التي عمل بها المبحوث

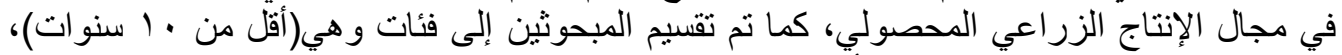

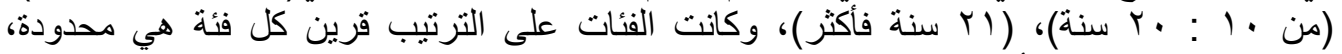

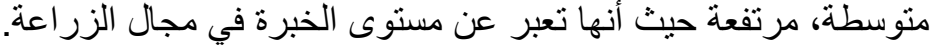

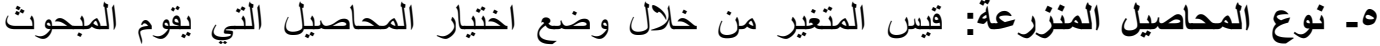

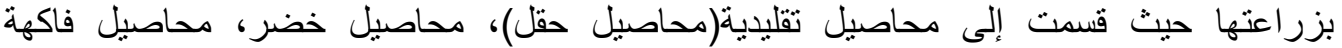

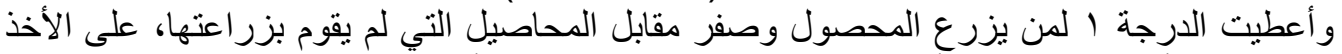

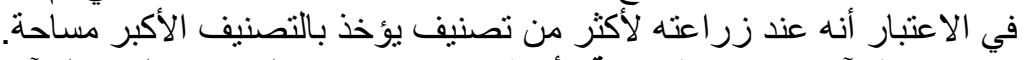

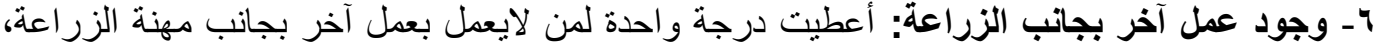

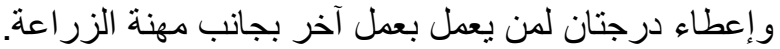

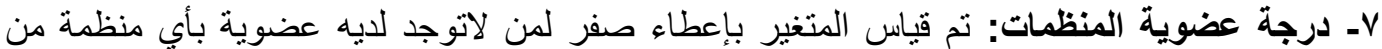

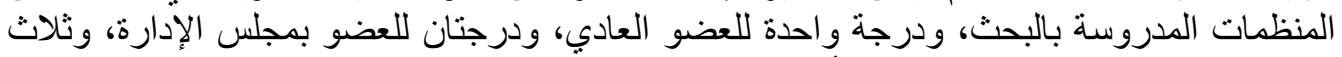

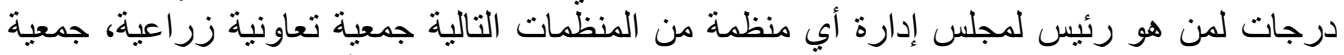

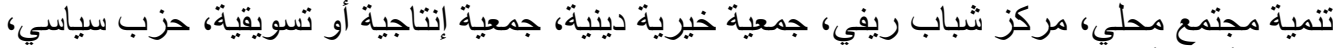

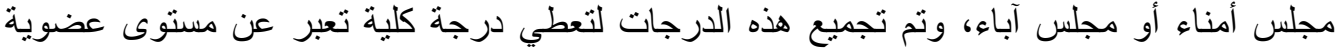

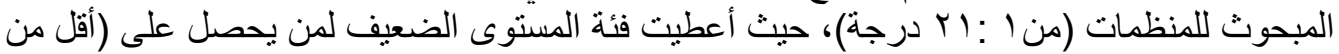

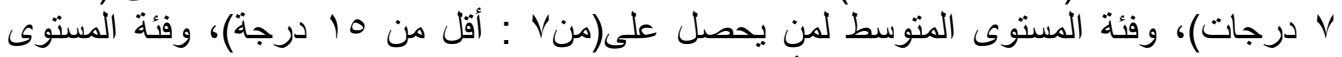

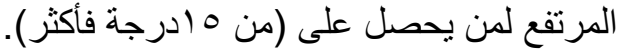

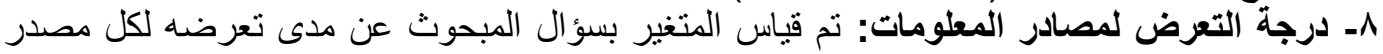

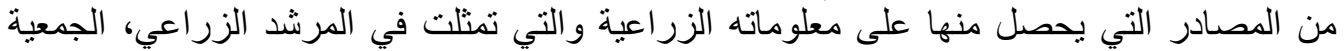

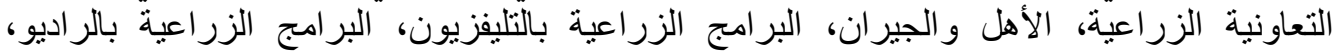

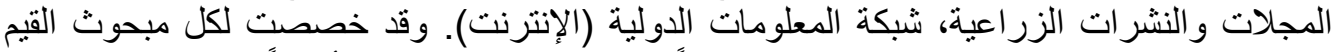

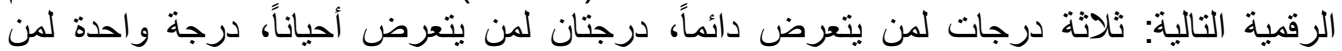

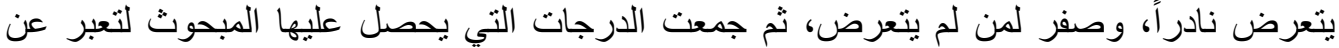

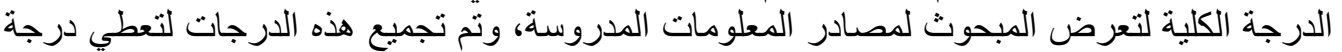

Fayoum J. Agric. Res. \& Dev., Vol. 30, No.2, July, 2016 
ITs

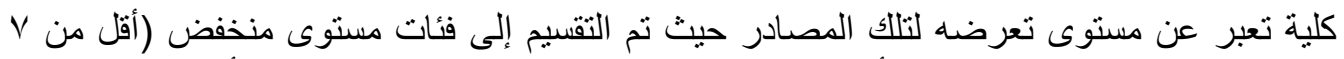

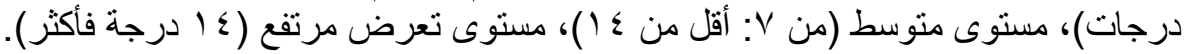

تثانيا : المتغير التابع دابع

لتحديد درجة اتجاهات المبحوثين نحو عودة الدورة الزراعية الإجبارية فقد نم استخدام مقياس

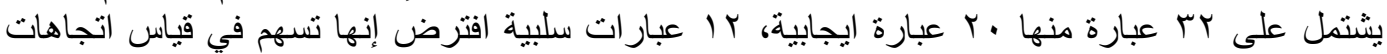

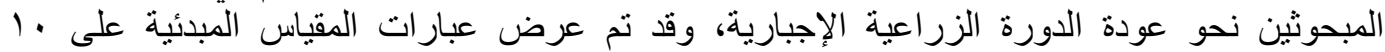

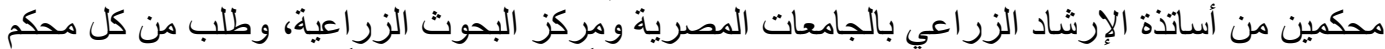

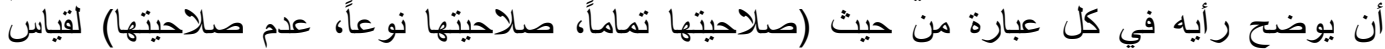

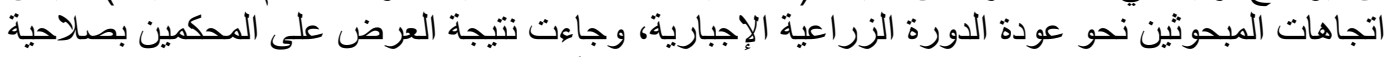

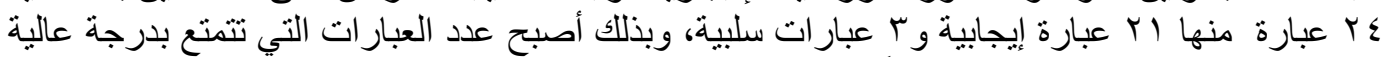

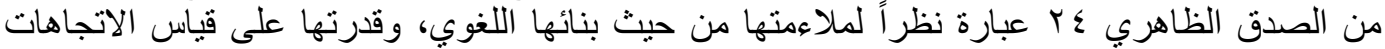

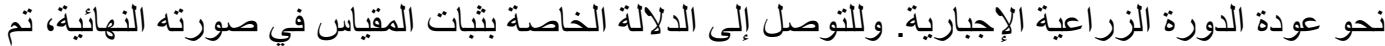

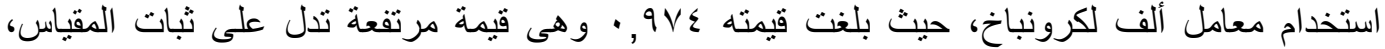

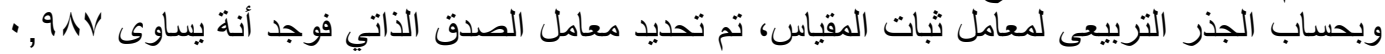
و هذا يعتبر معامل صدق مرتفع لهذا المقياس.

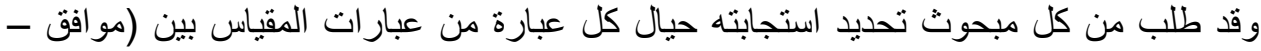

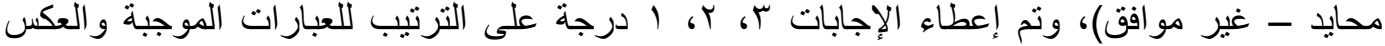

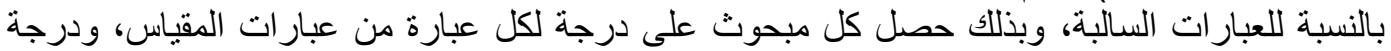

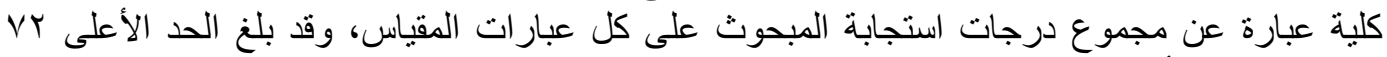

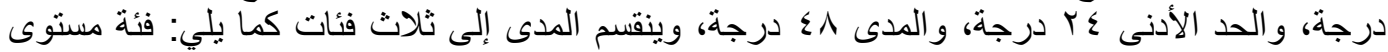

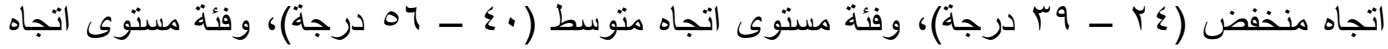

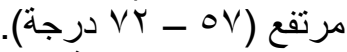

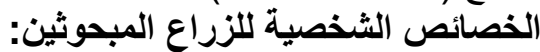

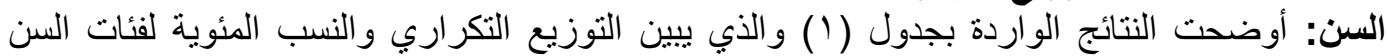

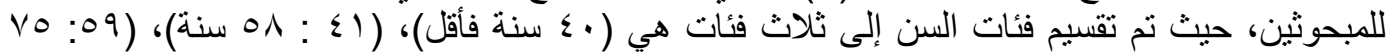

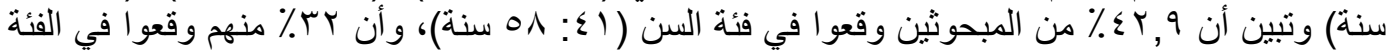

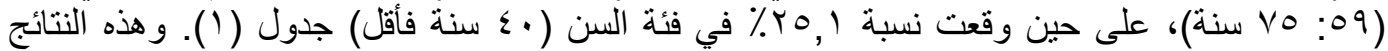

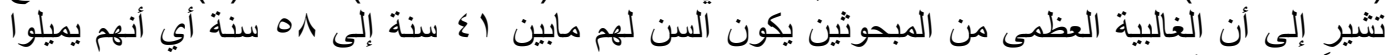

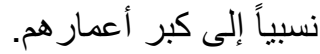

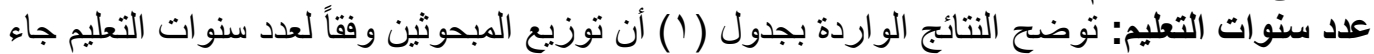

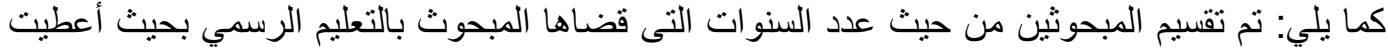

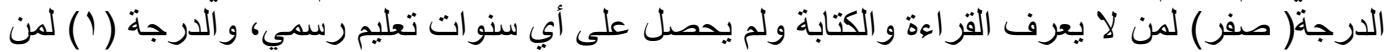

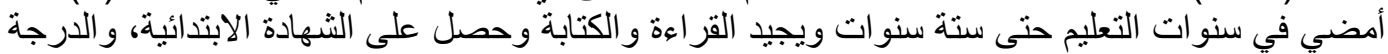

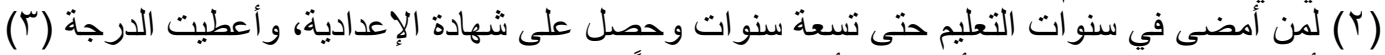

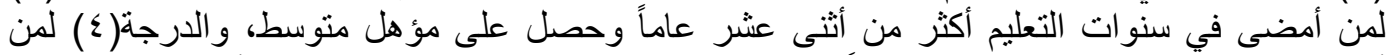

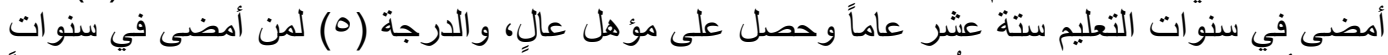

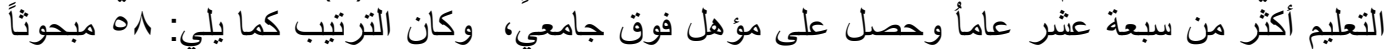

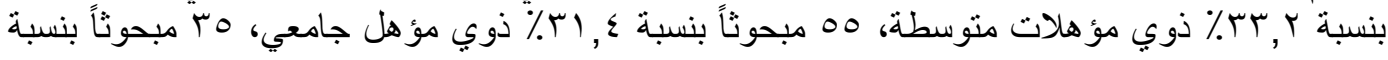

Fayoum J. Agric. Res. \& Dev., Vol. 30, No.2, July, 2016 
i ro

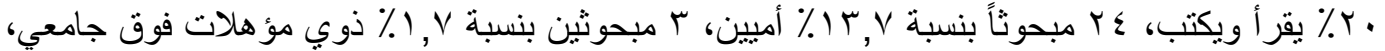

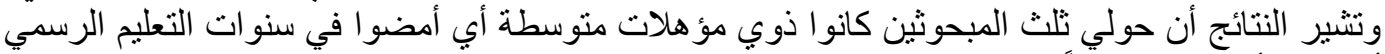
أكثر من أثنى عشر عانَاً.

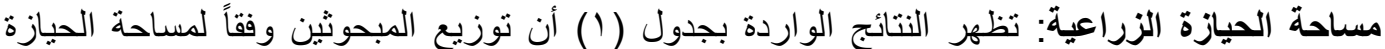

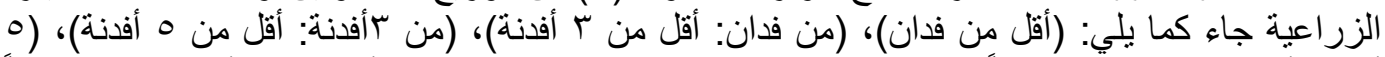

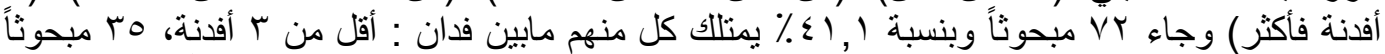

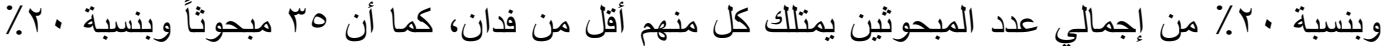

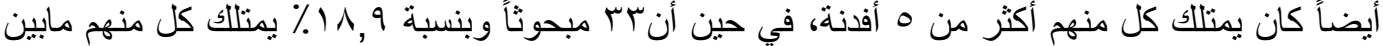

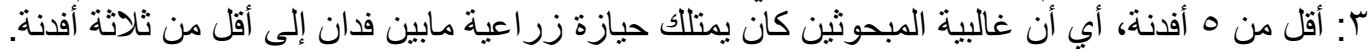

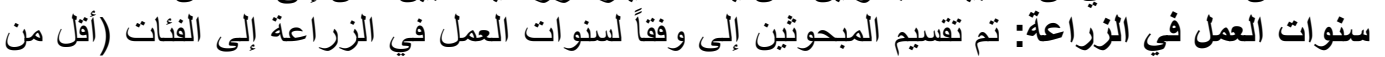

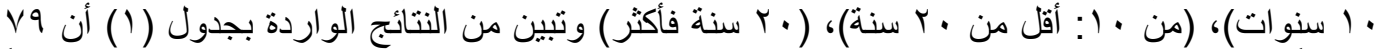

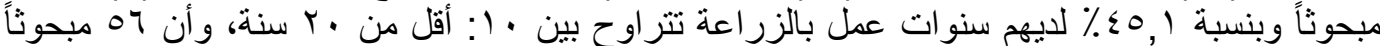

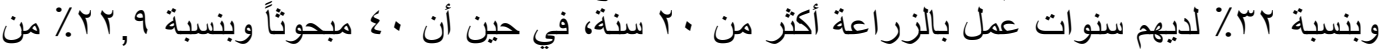

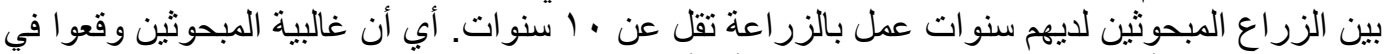

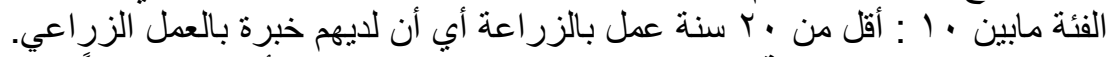

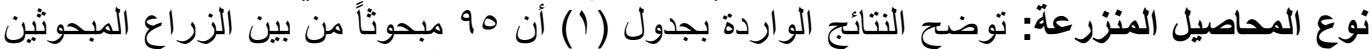

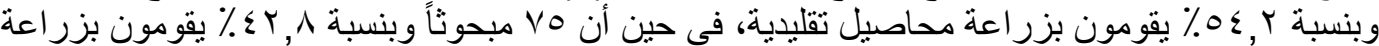

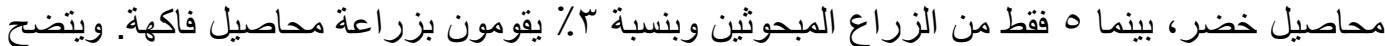

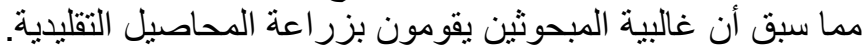

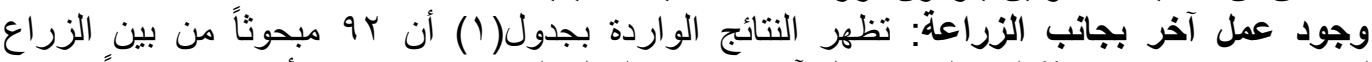

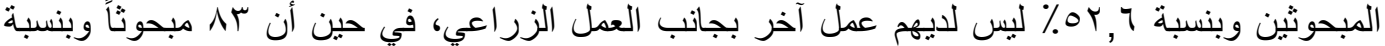

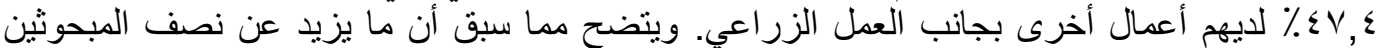
يعمل بالز الزاعة فقط. عضوية المنظمات: تبين من النتائج الو اردة بجدول ( ) أن جميع المبحوثين بنسبة .. (1 جاءوا في فئة

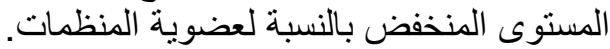

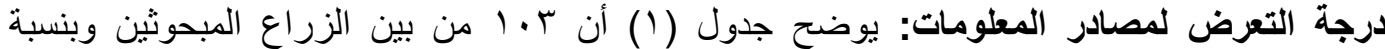

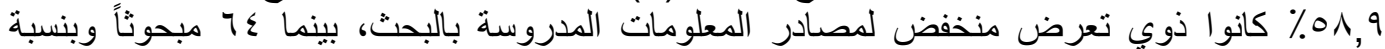

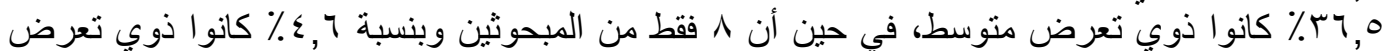

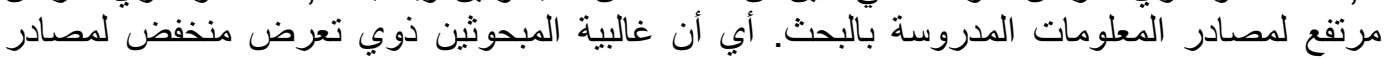

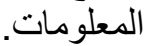

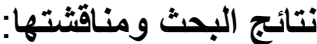

أولاً: اتجاهات الزراع المبحوثين نحو عودة الدورة الزراعية الإجبارية.

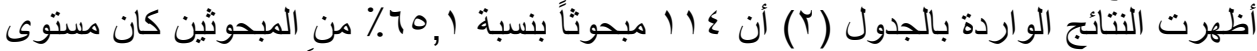

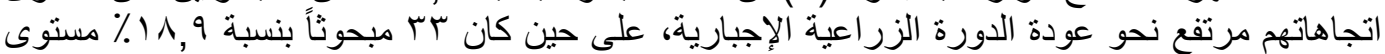

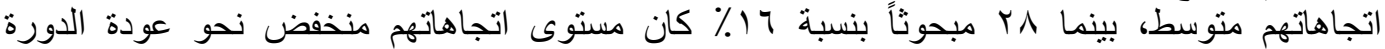

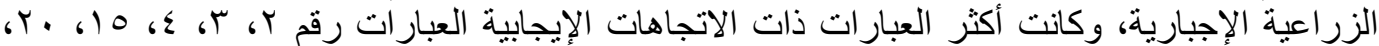

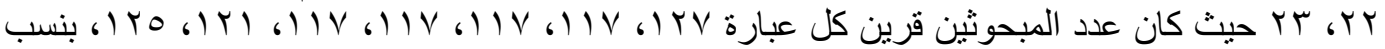

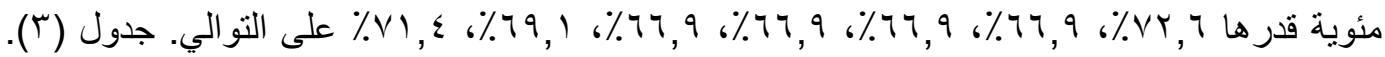

Fayoum J. Agric. Res. \& Dev., Vol. 30, No.2, July, 2016 
דצ

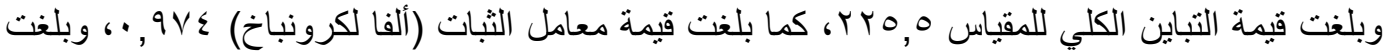

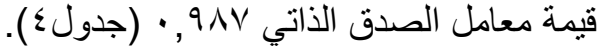

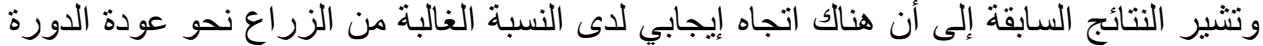

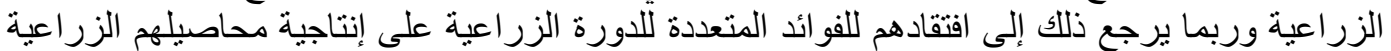

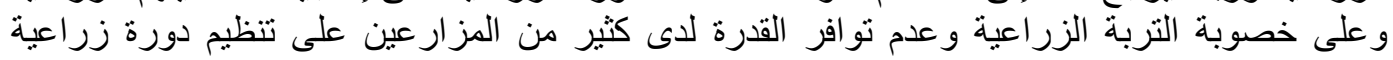

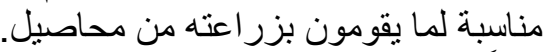

ثانياً: العلاقة الارتباطية بين اتجاهات الزراع المبحوثين وبين المتغيرات المستقلة المدروسة بالبحث.

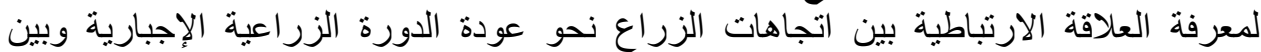

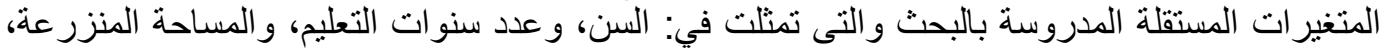

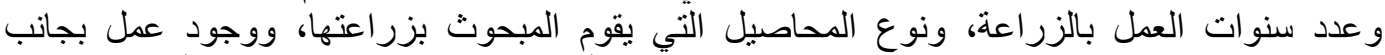

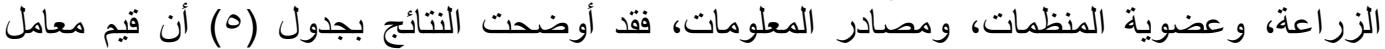

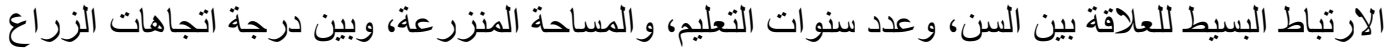

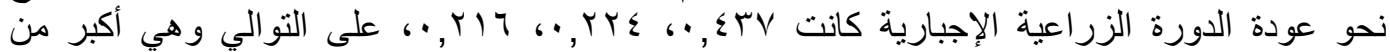

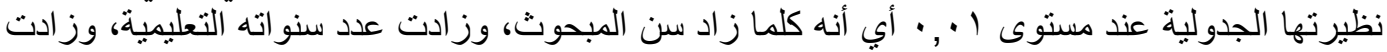

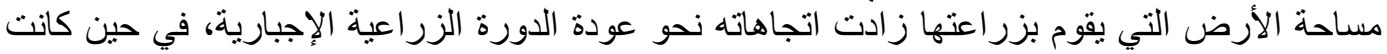

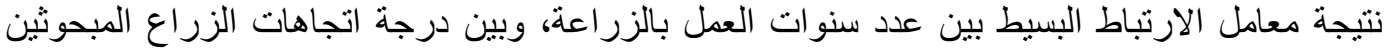

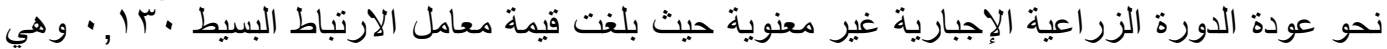

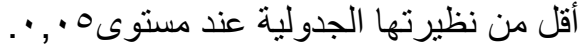

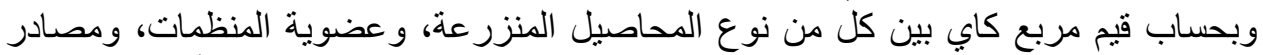

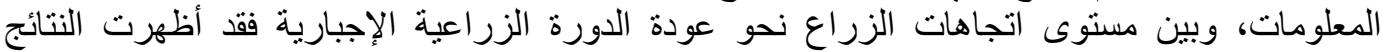

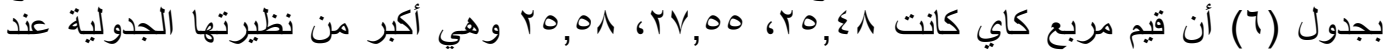
مستوى ا ', •، في حين كانت قيمة مربع كاي بين وجود عمل بجانب الزر إعة، وبين مستوى اتجاهات

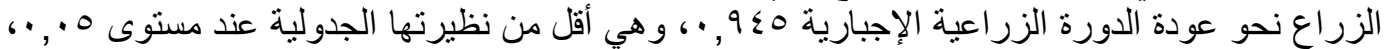

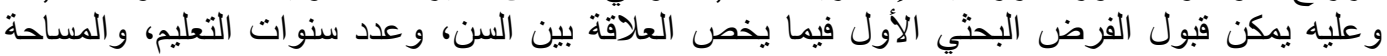

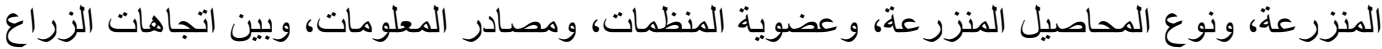
نحو عودة الدورة الزراعية الإجبارية، ومن ناحية أخرى يتم رفض الفرض البحني فيما يخص العلاقة بين

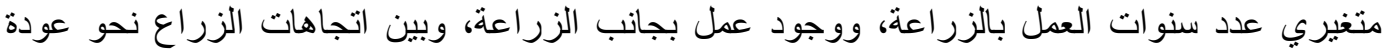

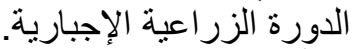
ثالثاً: تحديا نسبة إسهام المتغيرات المبارية المستقلة ذات الارتباط المعنوي في التباين الكلي المفسر للتغير في درجة اتجاهات الزراع نحو عودة الدورة الزراعيلة أسية الإجبارية.

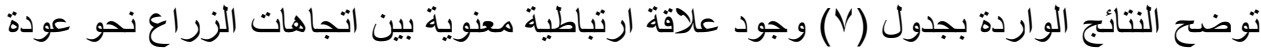
الدورة الزراعية الإجبارية كمتغير تابع، وبين كل من السن، وسنوات التعليم، و المساحة بالفدان كمتغيرات

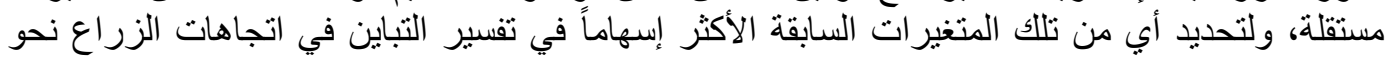
عودة الدورة الزراعية الإجبارية كان من الضروري وضع الفرض الإحصائي التالي " لايوجد إسهام

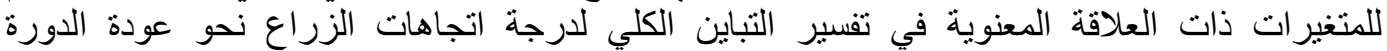

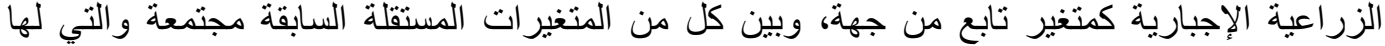

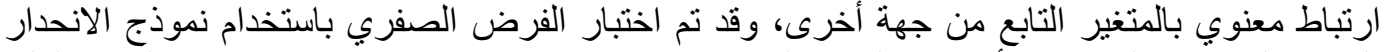

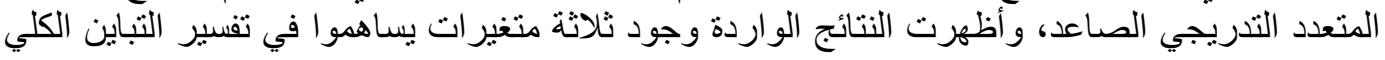

Fayoum J. Agric. Res. \& Dev., Vol. 30, No.2, July, 2016 
ITV

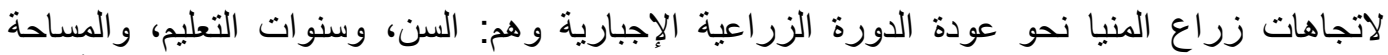

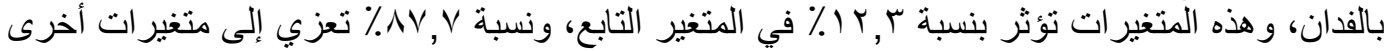

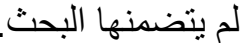

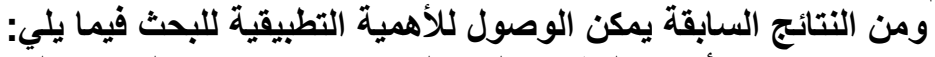

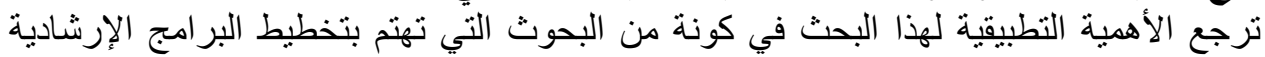

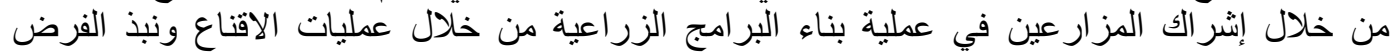

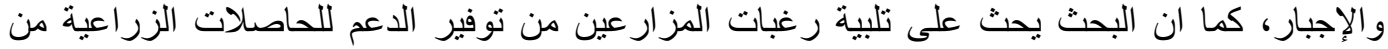

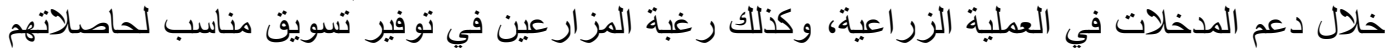

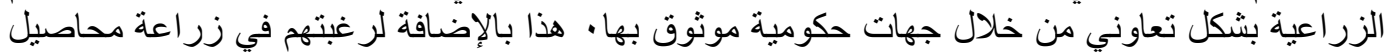

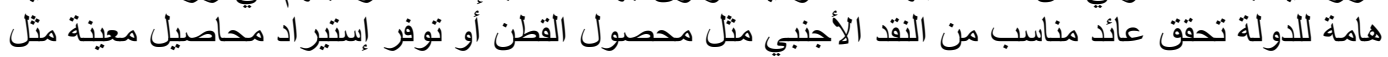

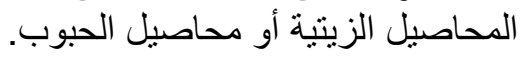

Fayoum J. Agric. Res. \& Dev., Vol. 30, No.2, July, 2016 
I TN

\begin{tabular}{|c|c|c|}
\hline$\%$ & ملة العدد & المتغيرات المستين وفقاً للمتغيرة \\
\hline $\begin{array}{l}r 0,1 \\
\varepsilon r, q \\
r r \\
1 \ldots\end{array}$ & $\begin{array}{l}\varepsilon \varepsilon \\
\text { Vo } \\
07 \\
\text { ivo }\end{array}$ & 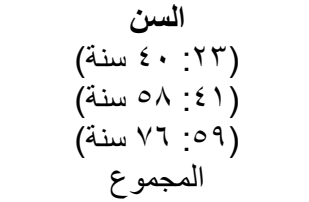 \\
\hline $\begin{array}{l}1 r, v \\
r, j \\
r r, r \\
r i, \varepsilon \\
1, v \\
1, .\end{array}$ & $\begin{array}{l}\text { rs } \\
\text { ro } \\
0 \wedge \\
00 \\
r \\
\text { ino }\end{array}$ & 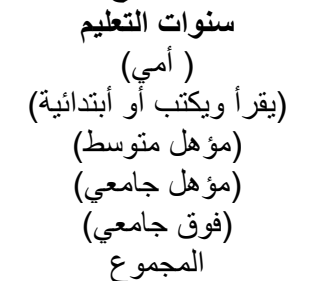 \\
\hline $\begin{array}{l}r . \\
\varepsilon 1,1 \\
11,9 \\
r . \\
1 \ldots\end{array}$ & $\begin{array}{l}\text { ing } \\
\text { ho } \\
\text { he } \\
\text { re } \\
\text { ho }\end{array}$ & 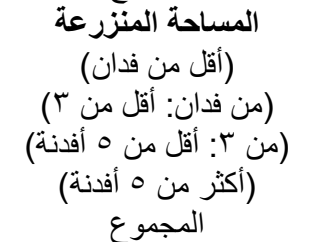 \\
\hline $\begin{array}{l}r y, q \\
\varepsilon 0,1 \\
r r \\
1 \ldots\end{array}$ & $\begin{array}{l}\varepsilon \\
89 \\
09 \\
180\end{array}$ & 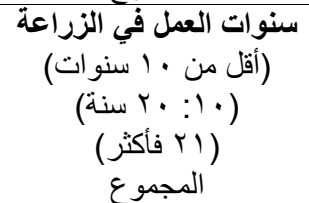 \\
\hline $\begin{array}{c}0 \leqslant, r \\
\varepsilon r, \wedge \\
r \\
1 \ldots\end{array}$ & $\begin{array}{l}90 \\
\text { vo } \\
0 \\
\text { ivo }\end{array}$ & 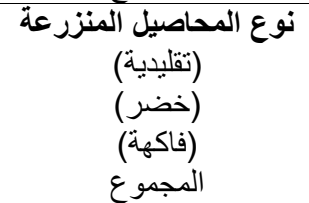 \\
\hline $\begin{array}{l}\varepsilon v, \varepsilon \\
0 r, q \\
1,\end{array}$ & $\begin{array}{l}\text { Ar } \\
q r \\
1 \ldots\end{array}$ & وجود عمل بجاتب الزراعة \\
\hline صفر & $\begin{array}{l}\text { IVo } \\
- \\
\text { ivo }\end{array}$ & 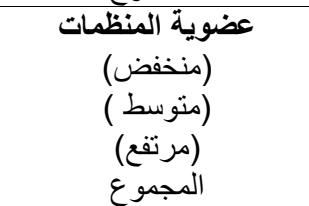 \\
\hline $\begin{array}{l}01,9 \\
r q, 0 \\
\varepsilon, 7 \\
1 \ldots\end{array}$ & $\begin{array}{l}1.4 \\
i \varepsilon \\
120\end{array}$ & $\begin{array}{c}\text { مصادر المعظومات (منخفض) } \\
\text { (متوسط) } \\
\text { (مرتفع) } \\
\text { (منفوع }\end{array}$ \\
\hline
\end{tabular}

Fayoum J. Agric. Res. \& Dev., Vol. 30, No.2, July, 2016 
جدول (ץ): توزيع المبحوثين وفقاً لمستوى الاتجاهات نحو عودة الدورة الزراعية الإجبارية.

\begin{tabular}{|c|c|c|}
\hline \multicolumn{2}{|c|}{ الإجمالي } & \multirow{2}{*}{ مستويات الاتجاهات } \\
\hline$\%$ & العدد & \\
\hline 17 & rA & منخفض ( ₹ : : Y درجة) \\
\hline 11,9 & 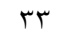 & متوسط (·ـ (؛: 07 درجة) \\
\hline 70,1 & $11 \varepsilon$ & مرتفع (OV: VY Y درجة) \\
\hline $1 \ldots$ & ivo & الإجمالي \\
\hline
\end{tabular}

جدول (r): توزيع المبحوثين وفقاً لاتجاهاتهم نحو عودة الدورة الزراعية الإجبارية لكل عبارة من

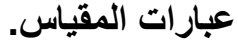

\begin{tabular}{|c|c|c|c|c|c|c|c|}
\hline \multicolumn{2}{|c|}{ غير موافق } & \multicolumn{2}{|c|}{ سيان } & \multicolumn{2}{|c|}{ 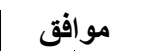 } & \multirow[t]{2}{*}{ العبارات } & \multirow[t]{2}{*}{ r } \\
\hline$\%$ & عدد & $\%$ & عدد & $\%$ & عدد & & \\
\hline$r \varepsilon$ & EY & $v, 1$ & & $\wedge, 9$ & $r$ & أعثقد أن عودة الدورة الزر اعية هيساعدني على مقاومة الآفات في أرضي & 1 \\
\hline $1 \leq, 9$ & YY & 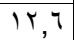 & & $V Y, T$ & & أرى أن عودة نظام الدورة الزر اعية بساعد في الحفاظ على خصوبة التربة & r \\
\hline 17 & rA & $\mid V .1$ & & 7,9 & $11 \mathrm{~V}$ & أرى أن عودة نظام الدورة الزر اعية بحقق التزبة التوازن في استغلال العناصر & $r$ \\
\hline$\varepsilon, 9$ & rT & $\Lambda, r$ & & 7,9 & & تطبيقي للاورة الزر اعية في أرضي يعمل على حسن الاستفادة من الطبقات & $\varepsilon$ \\
\hline$\varepsilon, 7$ & $\varepsilon$ & $r \varepsilon$ & & , 乞 & 70 & عودة الدورة الزر اعية هيساعدني على تنظيم العمل في أرضي. & 0 \\
\hline$r \uparrow, r$ & $\leqslant \uparrow$ & $r \cdot, q$ & 0 & $\varepsilon r, q$ & vo & أعتقد أن عودة الدورة الزر اعية سيحقق توزيع للإير ادات الزر اعية على مدار السذ & 7 \\
\hline$r \wedge, q$ & 71 & $r r, \varepsilon$ & $\leqslant 1$ & $r v, v$ & 77 & من وجهة نظري أن الدورة الزر اعية كانت بتساعد المزارع أنه مايخسرش. & $\mathrm{V}$ \\
\hline$r \varepsilon$ & $\varepsilon r$ & $r+, T$ & or & $\varepsilon r, \varepsilon$ & $\sqrt{ } 7$ & أعتقد أن الدورة الزراعية كانت بتساهم في توفير مياه الري. & $\wedge$ \\
\hline 17 & rA & $r, r$ & & $1, \mathrm{~V}$ & . & عودة الدورة الزر اعية هيساعد على زيادة انتاجية المحاصيل. & 9 \\
\hline 19,8 & $r \varepsilon$ & 17 & r & $\varepsilon, 7$ & & عودة الدورة الزراعية هيساعد الدولة في زر اعة محاصيل اقتصادية هامه. & 1. \\
\hline$r \leq, 7$ & $\varepsilon r$ & $0, \mathrm{~V}$ & $\varepsilon$ & $9, \mathrm{~V}$ & $\mathrm{NV}$ & اشعر ان ايام ماكانت فيه دورة زر اعية أفضل من الأيام الحالية. & 11 \\
\hline$r r, r$ & rq & $r \leqslant, 7$ & $\varepsilon r$ & or, 1 & ז & أفضل عودة نظام الدورة الزر اعية القديمة مرة ثانية & it \\
\hline$r_{0,1}$ & $\varepsilon \varepsilon$ & $r 7,9$ & & $\leqslant \wedge$ & & أتمنى أن كل المزارعين بطالبوا الحكومة بعودة الدورة الزر اعية & $1 \pi$ \\
\hline $19, \varepsilon$ & $r \varepsilon$ & 17 & YA & $7 \varepsilon, 7$ & $r$ & أنا شايف إن عودة الدورة الزر اعية تعني عودة قيمة المزارع المصري & $1 \leq$ \\
\hline$r \cdot, T$ & ru & $r, 0$ & rr & 77,9 & $11 \mathrm{~V}$ & 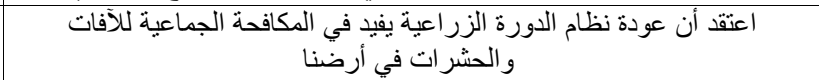 & 10 \\
\hline$r V, \varepsilon$ & $\varepsilon$ & , & & $\varepsilon$ & & أرفض عودة الدورة الزر اعية علشان أقدّر أزر ع المحصول اللي يعجبني & 7 \\
\hline$r v, \varepsilon$ & $\varepsilon \wedge$ & 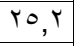 & $\varepsilon$ & $\mathrm{v}, \varepsilon$ & $\mathrm{NT}$ & من يوم مالغوا الدورة الزر اعية والزر اعة ضاعت & IV \\
\hline$r \leqslant, r$ & 7. & $\xi, r$ & 7. & $1, \varepsilon$ & & أفضل عودة الدورة الزراعية حتى ولو هخسر & 11 \\
\hline $\mathrm{v}, \varepsilon$ & 14 & $r \cdot, r$ & 0 & $\pi, r$ & 1 & المزارع الثاطر اللي ينفذ دورة زر اعية في أرضه & 9 \\
\hline 17,7 & rq & 7,0 & r & 77,9 & $11 \mathrm{~V}$ & اللي هيتبع الدورات الزر اعية زرعه كله هيخسر & $r$. \\
\hline $1 \wedge, r$ & rt & $r 7,7$ & $T \varepsilon$ & $\leqslant 0,1$ & $\vee 9$ & أيام ما كانت فيه دورة زر اعية كانت الناس بتساعد بعضيهه & YI \\
\hline ir & YI & 11,9 & Tr & 79,1 & $|r|$ & رغم إني مساحتي الزر اعية صغيرة إلا إنني حريص على إتباع دورة زراعية & tr \\
\hline IV,V & M & $1 \cdot, 9$ & 1 & $1, \varepsilon$ & 11 & أيام ماكانت الدورة الزر اعية كانت الناس بتسمع لكلام المرشد الزراعي. & rT \\
\hline$r, 9$ & $\varepsilon \cdot$ & rA & $\leqslant 9$ & $\leqslant 9,1$ & AT & اعتقد ان نظام الدورة الزراعية لايمكن تطبيقه حاليا في مصر & $\varepsilon$ \\
\hline
\end{tabular}

جدول(؛) ): الانحرافات المعيارية ومعاملات الارتباط البسيط بين كل عبارة من عبارات المقياس وبين

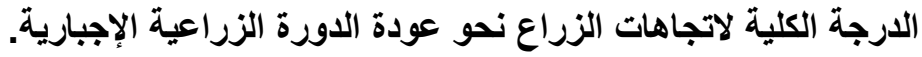

Fayoum J. Agric. Res. \& Dev., Vol. 30, No.2, July, 2016 
$1 \%$.

\begin{tabular}{|c|c|c|c|}
\hline الاتسات الداخلي (الارتباط) & الانحراف المعياري & التباين & رقم العبارة \\
\hline$* *,, \vee \backslash \leq$ & $\cdot, \wedge \leq \Psi$ & $\cdot, \times \vee 1$ & س1 \\
\hline${ }^{* *} \cdot, \vee \vee 94$ & $\cdot, \mathrm{VTN}$ & $\cdot, 0 \leq \leqslant$ & س \\
\hline$* *, \wedge \cdot \wedge$ & $\cdot, \mathrm{V} \circ \mathrm{V}$ & $\cdot, O V T$ & س山r \\
\hline **, , Атт & $\cdot, V \leqslant r$ & $\cdot, \infty$ & سع \\
\hline$* *, V \mu$. & $\cdot$ •, Arr & $\cdot, 79 r$ & س0 \\
\hline$\left.{ }^{* *} \cdot, \wedge\right) r$ & $\cdot, \Lambda \backslash \vee$ & $\cdot, 771$ & س7 \\
\hline$* *$, , TOr & $\cdot, \wedge \vee V$ & $\cdot, V \vee \cdot$ & س V \\
\hline${ }^{* *} \cdot, V \cdot r$ & $\cdot, \wedge \cdots$ & $\cdot, 7 \varepsilon$ & سى \\
\hline **., 9 Tr & $\cdot, \mathrm{V} 07$ & $\cdot, 0 \times 1$ & س99 \\
\hline${ }^{* *} \cdot, V \mu r$ & $\cdot, \wedge \ldots$ & $\cdot, 7 \varepsilon$. & س. \\
\hline${ }^{* *} \cdot, \wedge r r$ & $\cdot, \wedge r V$ & $\cdot, 7 \wedge \varepsilon$ & س \\
\hline${ }^{* *} \cdot, \wedge \vee 1$ & $\cdot, \lambda) \leq$ & $\cdot, 77 \pi$ & س \\
\hline **., АTV & $\cdot, \wedge Y \uparrow$ & $\cdot, T \wedge \mu$ & س \\
\hline${ }^{* *} \cdot$, AYr & $\bullet, \wedge \cdots$ & $\cdot, 7 \varepsilon$ & سع 1 \\
\hline${ }^{* *} \cdot, \wedge 71$ & $\cdot, 110$ & $\cdot, 77 \varepsilon$ & سم10 \\
\hline${ }^{* *} \cdot, \vee \vee \uparrow$. & $\cdot, \wedge r q$ & $\cdot, 7 \wedge V$ & س17 \\
\hline${ }^{* *} \cdot, 119$ & $\cdot, \wedge \leqslant \varepsilon$ & $\cdot, V / T$ & س IV \\
\hline${ }^{* *} \cdot, \mathrm{V} \uparrow \Lambda$ & $\cdot, \lambda I r$ & $\cdot, 77$. & س111 \\
\hline${ }^{* *} \cdot$, VOY & $\cdot, 7 \pi$ & $\cdot, r q \Lambda$ & (1919 \\
\hline${ }^{* *} \cdot, \mathrm{V} r q$ & $\cdot, \vee 70$ & $\cdot, 0 \wedge 0$ & س. \\
\hline${ }^{* *} \cdot, \vee \vee \vee \wedge$ & $\cdot, \mathrm{VOr}$ &., 070 & س ب \\
\hline${ }^{* *} \cdot, \wedge \leq 9$ & $\cdot, 799$ & $\cdot, \varepsilon \wedge \wedge$ & س \\
\hline${ }^{* *} \cdot, 101$ & $\cdot, \vee \vee \wedge$ & $\cdot, 7 \cdot 7$ & سبr \\
\hline$* *,, \vee \backslash V$ & $\cdot, 1 \cdot 9$ & $\cdot, 700$ & س \\
\hline
\end{tabular}

جدول (0): قيم معامل الارتباط البسيط بين اتجاهات الزراع نحو عودة الدورة الزراعية الإجبارية وبين المتغيرات المستقلة المدروسة الإئة

\begin{tabular}{|c|c|}
\hline 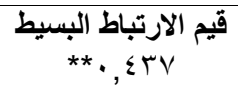 & المتغيرات المستقلة \\
\hline$* *, Y Y \zeta$ & عدد سنو ات التعليم \\
\hline${ }^{* *} \cdot, Y 17$ & المساحة المنزر عة (بالفدان) \\
\hline$\cdot, 1 \pi$. & عدد سنوات العمل بالزر اعة \\
\hline
\end{tabular}

جدول (†): قيم مربع كاي بين اتجاهات الزراع نحو عودة الدورة الزراعية الإجبارية وبين المتغيرات

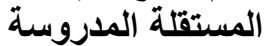
المتغيرات المستقلة الملروة

Fayoum J. Agric. Res. \& Dev., Vol. 30, No.2, July, 2016 
$\mid T 1$

\begin{tabular}{|c|c|c|}
\hline$* *, r \circ V$ & $* * Y 0, \leqslant \wedge$ & نوع المحاصيل المنزر عة \\
\hline$\cdot, \cdot V \mu$ & $\cdot, 9 \leqslant 0$ & وجود عمل بجانب الزراعة \\
\hline$* *, r 79$ & $* * Y Y, 00$ & عضوية المنظمات \\
\hline${ }^{* *} \cdot$, rOV & $* * Y_{0,01}$ & مصادر المعلومات \\
\hline
\end{tabular}

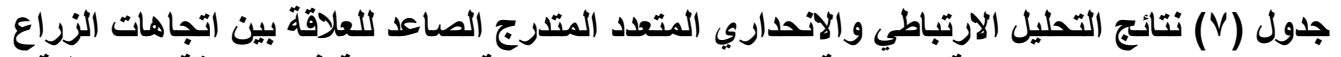

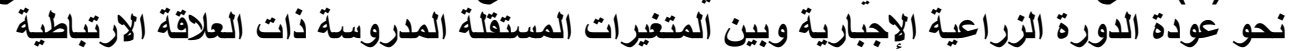

\begin{tabular}{|c|c|c|c|c|c|}
\hline قالمسمة فية & 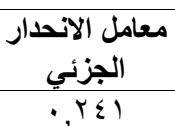 & 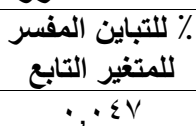 & ا المفرللمتنغير التبابيع & معامل الارتباط & المتغير التسنيل الداخل \\
\hline$* * 9,1 \wedge$ & $\cdot, \vee \vee \wedge$ & $\cdot .0$. &., 0. & $\cdot, Y Y \leqslant$ & سنو ات التعليح \\
\hline${ }^{* *} \wedge, \cdot r$ & $\cdot, V Y Y$ & $\cdot, \cdot Y 7$ & $\cdot, I Y \mu$ & $\cdot, r 01$ & المساحة بالفدان \\
\hline
\end{tabular}

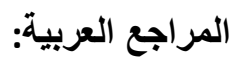

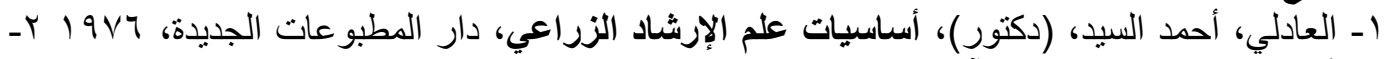

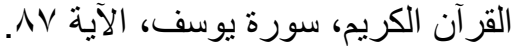

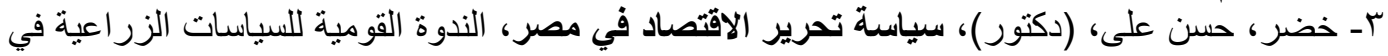

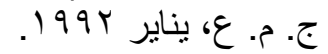
ع- خطاب، حسن عبدابل عندمن، الثروة النباتية في مصر القديمة، الإدارة العامة للثقافة الزراعية، القاهرة، .1910

هـ خطاب، حسن عبدالرحمن، الثروة النباتية في مصر القديمة، الإدارة العامة للثقافة الزراعية، القاهرة، .1910

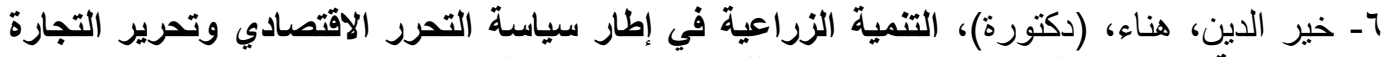

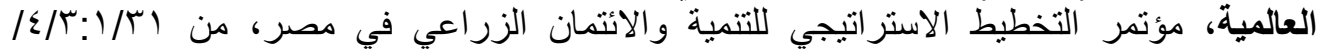
199V V- زهران، حامد عبد السلام،(دكتور)، علم النفس الاجتماعي، عالم الكتب، الطبعة الرابعة، القاهرة، I $19 \vee \mathrm{V}$

ᄉ- سالم، سالم حسين، علاقة اتجاهات وقيم المزارعين المصريين برفض الممارسات المستحدثة، رسالة

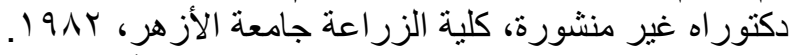

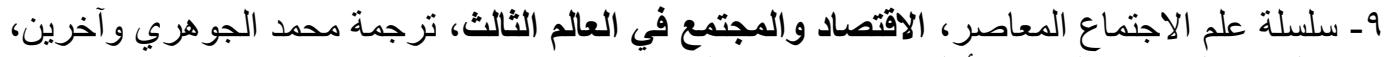

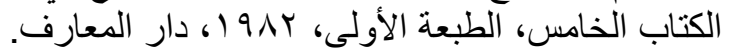

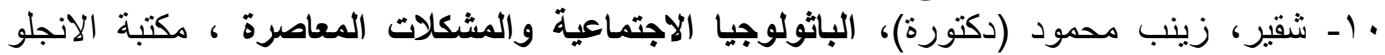

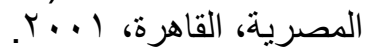

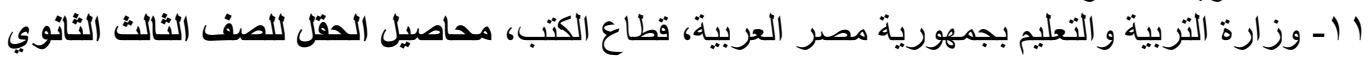

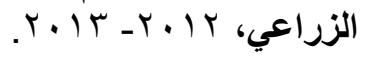

1. Allport. Gordon. Attitude. Benign book. 1960.

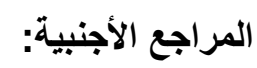

Fayoum J. Agric. Res. \& Dev., Vol. 30, No.2, July, 2016 
Irt

2. Bradfield, D.I. Guide to Extension Training. F.A.O., Roma, 1966.

3. Katz, D., \&Stotland. A preliminary Statement A theory of Attitude and change. In Sigmund Koch, (ed) Psychology Astudey of Science. Vol. 8.Mc Grow. Hill. N. Y.. 1959. In Summers op, Sit.

4. Merton. Robert. Social Theory and Social Structure. U.S.A. 1962.

5. Persons, T., The Social System, N.Y., the Free press. 1951.

6. Summers, Dene,(ed) Attitude measurement .R and Mc nelly company. U.S.A, 1970.

7. Wagner. Richard \& Sherwod. The Study of Attitude Change. Wad worth pub. Comp. Inc. 1969.

8. www.Sakregypt.7p.com/menya.htm, visited date $، 25 / 6 / 2016$.

\title{
FARMERS ATTITUDES TOWARDS THE RETURN OF MANDATORY AGRICULTURAL ROTATION IN SOME VILLAGES OF MINIA GOVERNORATE
}

\section{Dr: Hamdy El Sherif}

Researcher in the Agricultural Extension and Rural Development Institute

\begin{abstract}
The research aimed at determining the attitudes of the farmers respondents towards the return of the mandatory of agricultural rotation, determining the relationship between the independent variables and the farmers attitudes, and determining the contribution of each related independent variables in explaining the variation in the farmers attitudes towards the return of the mandatory agricultural rotation.

The study was done in minia governorate which were selected randomly, three randomly centers were also selected and one village from each center was selected randomly to be located in the north, the middle and the south of the governorate, these villages were: Elgendia in Beni mazar, Mahdya in Elminia, and Nazlet Tona in Mallawy.

A sample of 175 respondents representing $10 \%$ of the total farmers were selected randomly and systematically from the records of agricultural cooperatives in the selected villages.

Data was collected through personal interviews by using pretested questionnaire in June 2016. Frequencies, percentages simple correlation, chi-
\end{abstract}

Fayoum J. Agric. Res. \& Dev., Vol. 30, No.2, July, 2016 
Tr

square, compatibility coefficient and multiple correlation, and regression were used to present and analyze data statistically.

The results showed that:

$65 \%$ of the respondents had a high level of attitudes towards the return of the mandatory agricultural rotation, while $18.9 \%$ of them had a moderate level of attitudes, and $16 \%$ had a low level of attitudes.

The result showed that there was significant relation between the level of education, the grown area, the crop, the membership of organization, the source of information and the farmers' attitudes towards the return of mandatory agricultural rotation. The results showed that there were three variables that contributed by $12.7 \%$ in explaining the variation in the farmers' attitudes towards mandatory agricultural rotation which were age, education and grown area.

Fayoum J. Agric. Res. \& Dev., Vol. 30, No.2, July, 2016 